\title{
Adaptive Particle Swarm Optimization Using Information about Global Best
}

\author{
Teruyoshi Yamaguchi Student Member (Tokyo Metropolitan University, Japan) \\ Nobuhiro Iwasaki Member (Tokyo Metropolitan University, Japan) \\ Keiichiro Yasuda Member (Tokyo Metropolitan University, Japan)
}

Keywords: Global Optimization, Swarm Intelligence, Particle Swarm Optimization, Adaptive Algorithm.

The Particle Swarm Optimization method is one of the most powerful optimization methods available for solving global optimization problems. The PSO method was originally proposed by J. Kennedy et al. as an optimization method in 1995. Subsequent numerical experiments have demonstrated that the PSO method is efficient for a variety of global optimization problems having nonlinear and multipeaked features.

However, knowledge of adaptive strategies for tuning the parameters of the method for application to large-scale nonlinear non-convex optimization problems is as yet limited. This paper describes an adaptive strategy for tuning the parameters of the PSO method based on some numerical analysis of the behavior of PSO.

This paper proposes a new adaptive PSO algorithm. The proposed adaptive tuning strategy is based on self-tuning of the parameters of PSO, which strategy utilize the information about the frequency of an updated global best of a swarm. The feasibility and advantages of the proposed adap- tive PSO algorithm are demonstrated through some numerical simulations using two typical global optimization test problems.

Tables 1 and 2 list the simulation results of applying the conventional parameter-fixed PSO (PSO), the Linear Decrease Inertia Weight Approach (LDIWA) and the proposed Adaptive PSO (APSO) to two types of typical benchmark problems $-2^{n}$ minima function and Griewank function.

Using the strategy of the LDIWA for the adjustment of parameter $w$, while a diversification in the search is realized in the initial stage, an intensification in the search is realized in the final stage of the search. From these numerical experiments, the search ability of the LDIWA is reduced when the scale of the problem becomes large.

However, Tables 1 and 2 clarify that the search ability of the proposed Adaptive PSO (APSO) doesn't decreases when the scale of the problem becomes large. Based on these tables, the proposed method is also confirmed to have higher optimality than the LDIWA.

Table 1. Application results for $f_{1}: 2^{n}$ minima function $\left(T_{\max }=500\right)$

\begin{tabular}{|c|c|c|c|c|c|c|c|c|c|c|c|c|c|}
\hline \multirow{2}{*}{$\begin{array}{c}f_{1} \\
\text { Dim. }\end{array}$} & \multirow{2}{*}{$\begin{array}{c}\text { Global } \\
\text { optimum }\end{array}$} & \multicolumn{3}{|c|}{ Best value } & \multicolumn{3}{|c|}{ Mean value } & \multicolumn{3}{|c|}{ Worst value } & \multicolumn{3}{|c|}{ Standard deviation } \\
\hline & & PSO & LDIWA & APSO & PSO & LDIWA & APSO & PSO & LDIWA & APSO & PSO & LDIWA & APSO \\
\hline 10 & -783.3 & -783.3 & -783.3 & -783.3 & -744.8 & -774.5 & -761.2 & -668.4 & -726.7 & -698.5 & 31.4 & 15.4 & 24.6 \\
\hline 20 & -1566.6 & -1210.6 & -1566.6 & -1538.3 & -846.4 & -1447.1 & -1396.3 & -620.4 & -1340.4 & -1255.6 & 135.9 & 47.1 & 58.3 \\
\hline 30 & -2349.9 & -1454.4 & -2261.4 & -2207.6 & -1030.3 & -2086.3 & -2034.1 & -654.5 & -1922.6 & -1844.5 & 162.6 & 71.1 & 73.1 \\
\hline 40 & -3133.2 & -1737.0 & -2874.4 & -2905.2 & -1219.8 & -2608.0 & -2655.8 & -788.9 & -2235.8 & -2442.9 & 210.1 & 103.3 & 97.0 \\
\hline 50 & -3916.5 & -2072.1 & -3339.4 & -3474.1 & -1401.1 & -2923.7 & -3225.5 & -948.0 & -2338.6 & -2991.6 & 202.7 & 184.5 & 106.3 \\
\hline 60 & -4699.8 & -2172.9 & -3623.8 & -4123.8 & -1579.8 & -2893.3 & -3755.0 & -1120.5 & -1797.1 & -3388.2 & 228.4 & 398.7 & 138.7 \\
\hline 70 & -5483.1 & -2390.1 & -3808.9 & -4621.5 & -1729.1 & -2696.8 & -4223.8 & -1163.0 & -1218.1 & -3715.6 & 259.2 & 535.6 & 175.9 \\
\hline 80 & -6266.4 & -2495.3 & -3490.4 & -5218.9 & -1919.4 & -2495.4 & -4720.1 & -1123.2 & -1541.9 & -3498.2 & 285.4 & 529.1 & 216.0 \\
\hline 90 & -7049.7 & -2920.3 & -3649.3 & -5741.1 & -2120.6 & -2344.0 & -5146.4 & -1401.9 & -1647.6 & -3565.8 & 318.1 & 411.5 & 293.6 \\
\hline 100 & -7833 & -3025.1 & -3892.5 & -6166.1 & -2171.5 & -2433.5 & -5537.7 & -1556.2 & -1499.0 & -3972.2 & 297.6 & 391.6 & 313.1 \\
\hline
\end{tabular}

Table 2. Application results for $f_{2}:$ Griewank function $\left(T_{\max }=500\right)$

\begin{tabular}{|c|c|c|c|c|c|c|c|c|c|c|c|c|c|}
\hline \multirow{2}{*}{$\begin{array}{r}f_{1} \\
\text { Dim. }\end{array}$} & \multirow{2}{*}{$\begin{array}{c}\text { Global } \\
\text { optimum }\end{array}$} & \multicolumn{3}{|c|}{ Best value } & \multicolumn{3}{|c|}{ Mean value } & \multicolumn{3}{|c|}{ Worst value } & \multicolumn{3}{|c|}{ Standard deviation } \\
\hline & & $\mathrm{PSO}$ & LDIWA & APSO & PSO & LDIWA & APSO & $\mathrm{PSO}$ & LDIWA & APSO & $\mathrm{PSO}$ & LDIWA & APSO \\
\hline 10 & 0 & 0.11 & 0.00 & 0.02 & 0.50 & 0.11 & 0.13 & 0.97 & 0.28 & 0.41 & 0.20 & 0.06 & 0.09 \\
\hline 20 & 0 & 2.28 & 0.01 & 0.00 & 17.26 & 0.16 & 0.10 & 68.59 & 0.71 & 0.65 & 14.20 & 0.14 & 0.12 \\
\hline 30 & 0 & 45.73 & 0.80 & 0.05 & 96.85 & 1.06 & 0.67 & 130.24 & 1.23 & 1.86 & 17.67 & 0.07 & 0.35 \\
\hline 40 & 0 & 79.11 & 1.22 & 0.44 & 137.78 & 1.86 & 1.16 & 177.89 & 3.28 & 2.86 & 18.56 & 0.47 & 0.35 \\
\hline 50 & 0 & 141.30 & 2.50 & 0.95 & 185.24 & 5.15 & 1.87 & 243.41 & 14.87 & 5.37 & 19.54 & 2.18 & 0.81 \\
\hline 60 & 0 & 177.73 & 4.94 & 1.40 & 236.14 & 12.44 & 3.48 & 275.25 & 26.33 & 12.62 & 21.01 & 4.21 & 2.00 \\
\hline 70 & 0 & 205.65 & 9.21 & 1.90 & 279.12 & 24.53 & 4.91 & 334.56 & 45.72 & 13.70 & 21.82 & 6.94 & 2.12 \\
\hline 80 & 0 & 267.97 & 20.34 & 2.74 & 328.83 & 40.82 & 8.52 & 370.32 & 67.40 & 23.43 & 21.25 & 9.62 & 3.64 \\
\hline 90 & 0 & 324.53 & 33.51 & 4.97 & 376.35 & 64.53 & 13.41 & 446.10 & 103.06 & 60.85 & 21.67 & 14.87 & 6.89 \\
\hline 100 & 0 & 342.81 & 49.12 & 7.54 & 421.11 & 90.89 & 18.88 & 474.18 & 138.69 & 35.79 & 26.24 & 17.28 & 6.17 \\
\hline
\end{tabular}




\title{
最良解情報を用いた適応型 Particle Swarm Optimization
}

\author{
学生員 山口 晃歓* 正 員 岩崎 信弘* \\ 正 員 安田 恵一郎*
}

Adaptive Particle Swarm Optimization Using Information about Global Best

Teruyoshi Yamaguchi*, Student Member, Nobuhiro Iwasaki*, Member, Keiichiro Yasuda*, Member

The Particle Swarm Optimization method is one of the most powerful optimization methods available for solving global optimization problems. However, knowledge of adaptive strategies for tuning the parameters of the method for application to large-scale nonlinear non-convex optimization problems is as yet limited. This paper describes an adaptive strategy for tuning the parameters of the PSO method based on some numerical analysis of the behavior of PSO. The proposed adaptive tuning strategy is based on self-tuning of the parameters of PSO, which strategy utilize the information about the frequency of an updated global best of a swarm. The feasibility and advantages of the proposed adaptive PSO algorithm are demonstrated through some numerical simulations using three different typical global optimization test problems.

キーワード : 大域的最適化, Swarm Intelligence, Particle Swarm Optimization, 適応型アルゴリズム

Keywords: Global Optimization, Swarm Intelligence, Particle Swarm Optimization, Adaptive Algorithm.

\section{1. はじめに}

システムの大規模化・複杂隹化, 運用・制御における要求 の高度化を背景に, 高い最適性と実行可能性を併せ持つ最 適解を実用的な計算量で求めることが可能な最適化手法の 開発がシステム工学における重要な課題となっている。

実際にシステムの最適化を行う際には, 適用する手法が 扱えるクラスの問題となるように, また可能な限りモデル と実際のシステムとの乘离隹を抑えるように最適化すべきシ ステムをモデル化・定式化しなければならない。従って，扱 える問題のクラスに課す条件, 例えば目的関数や制約関数 の連続性や微分可能性などの条件が少ない手法は，より詳 細なモデルが使用できるなど工学的観点からは高い汎用性 を持つことになる。

Particle Swarm Optimization (以下, PSO) はメタヒ ユーリスティクス (発見的手法) の1つであり, 最適化問題 を解くための有力な手法の 1 つとして知られている。これ までに数多くの数値実験の結果から，連続型多峰性関数の 大域的最適解を実用的な計算時間内に高い精度で求めるこ とが可能なことが数值実験的に明らかにされてきた ${ }^{(2)(3)}$ 。

PSO は, 目的関数の連続性や微分可能性を必要とせず,

\footnotetext{
* 東京都立大学大学院

₹ 192-0397 東京都八王子市南大沢 1-1

Tokyo Metropolitan University

1-1, Minamiosawa, Hachioji-shi, Tokyo 192-0397
}

目的関数值情報のみを用いて多峰構造の無制約最適化問題 を解くことが可能であることから，工学分野において詳細 に記述された多くの複杂隹な問題に対して適用できる可能性 が高い。ところで, PSO を始めとする発見的手法の多くは， アルゴリズム内に調整すべきいくつかのパラメータを有し ており，これらのパラメータ設定の自由度により幅広い問 題を効率的に解いているが, 工学的応用を踏まえれば，パ ラメータ設定は解くべき問題に応じて, アルゴリズム内で 自律的・適応的に調整されることが望ましい。

しかしながら，PSO のパラメータ設定に関する研究は， パラメータ固定型，スケジューリング的調整則 ${ }^{(2)}$, 反応的 調整則 ${ }^{(4)(5)}$ に関する研究が主として行われてきており, 適 応的調整則に関する研究 ${ }^{(8)}$, あるいは自律適応的調整則に 関する研究は十分には行われていないのか現状である。

本論文では, 上述のことを踏まえ, PSO の探索過程で得 られる最良解更新情報を利用した適応型 PSO に関する検討 を行い, 新たな適応的アルゴリズムを構築した。具体的には， 最良解更新頻度が高い Particle のパラメータ値に漸近する ようにパラメータを適応的に調整する適応型 PSO アルゴ リズムを構築し, 典型的なベンチマーク問題である Rosenbrock's saddle 関数, $2^{n}$ minima 関数および Griewank 関 数を用いて提案手法の有用性を検証した。

\section{PSO の概要と最適化アルゴリズムの適応性}

〈2 1〉 PSO の概要 PSO は元々 2 次元空間上で群れ 


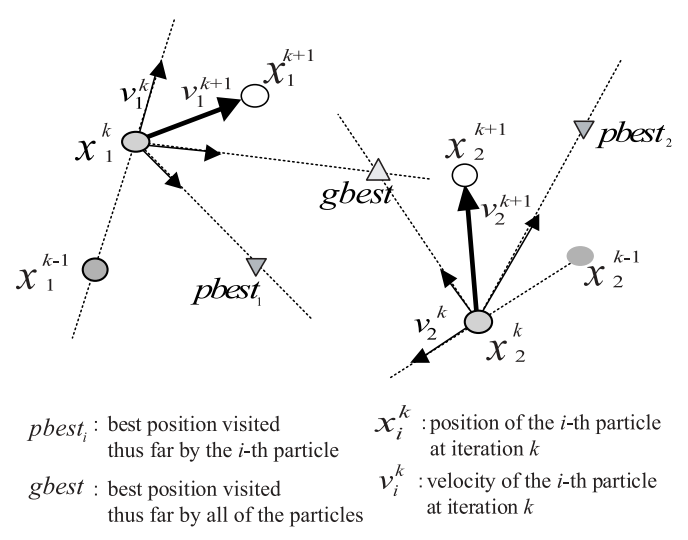

図 1 Particle の移動

Fig. 1. Movement of Particles.

の動きをシミュレーションする過程から開発された手法で あるが, 最適化手法としての PSO は多次元空間に拡張する ことができる。 $n$ 次元空間における $i$ 番目の Particle（探索 点) の位置は $n$ 次元べクトルによって $\boldsymbol{x}_{i}=\left(x_{i 1}, x_{i 2}, \ldots\right.$, $\left.x_{i j}, \ldots, x_{i n}\right)^{\mathrm{T}}$ と表される。ここで $i$ は Particle の番号を， $x_{i j}$ は $i$ 番目の Particle の位置ベクトルの第 $j$ 次元成分を表 す。また, 各 Particle は位置ベクトルの他に移動ベクトル $\boldsymbol{v}_{i}=\left(v_{i 1}, v_{i 2}, \ldots, v_{i j}, \ldots, v_{i n}\right)^{\mathrm{T}}$ を持っている。さらに, 各 Particleはこれまでに自身か探索を行ってきた中で最良の評 価值を与える位置ベクトル pbest $_{i}=$ pbest $_{i 1}$, pbest $_{i 2}, \ldots$, pbest $_{i j}, \ldots$, pbest $\left._{i n}\right)^{\mathrm{T}}$ と，关の評価値 $f\left(\right.$ pbest $\left._{i}\right)$ を記憶し ている。群れ全体としては，すべての Particleがこれまで 探索を行ってきた中で最良の評価値を与える位置べクトル $\boldsymbol{g} \boldsymbol{b e s t}=\left(\text { gbest }_{1}, \text { gbest }_{2}, \ldots, \text { gbest }_{j}, \ldots, \text { gbest }_{n}\right)^{\mathrm{T}}$ と，光 の評価值 $f$ (gbest) を記憶している。

各 Particle は自身が過去に発見した最良解「pbest」へ 向かうべクトル，群れ全体の最良解「gbest」へ向かう心゙ クトル，および前回の移動ベクトル $\boldsymbol{v}^{k}$ の線形結合として 新たな移動べクトル $\boldsymbol{v}^{k+1}$ を生成し, 次の位置 $\boldsymbol{x}^{k+1}$ に移 動する (図 1)。k+1 回目の移動で Particle $i$ が移動する 際， $n$ 次元空間における $j$ 番目の直交座標軸に射影される 移動べクトル $v_{i j}^{k+1}$ は次式で与えられる。

$$
\begin{aligned}
v_{i j}^{k+1}=w \cdot v_{i j}^{k} & +c_{1} \cdot \operatorname{rand}_{1}() \cdot\left(\text { pbest }_{i j}^{k}-x_{i j}^{k}\right) \\
& +c_{2} \cdot \operatorname{rand}_{2}() \cdot\left(\text { gbest }_{j}^{k}-x_{i j}^{k}\right)
\end{aligned}
$$

ただし, $\operatorname{rand}_{1}(), \operatorname{rand}_{2}()$ は 0 から 1 までの一樣乱数,$w$, $c_{1}, c_{2}$ は乥れ光れの項に対する重み係数である。上付きの 添え字 $k$ は反復回数を，下付きの添え字 $i$ は Particle 番 号を, $j$ は次元の番号を表す。PSO において移動ベクトル $v_{i j}^{k+1}$ は慣例的に速度とも呼ばれる。このときの移動は次式 によって行われる。

$$
x_{i j}^{k+1}=x_{i j}^{k}+v_{i j}^{k+1} .
$$

〈2. 2〉 最適化アルゴリズムの適応性一般に, シス テムにおける適応性は,「自己の内部構造をある法則に従っ
て調整する機能を備えていること」と定義されている。よ り具体的には,「システムの内部構造が一群の可変パラメー タによって規程されており，目的とする情報処理作業がよ り適切に遂行されるように, 可変パラメータがある法則に 従って自己調整されること」と定義される(1)。

この定義に従えば，最適化アルゴリズムにおける適応性 は,「アルゴリズムの内部構造が, 一群の可変パラメータに よって規程されており, 目的とする最適解探索がより適切 に遂行されるように，可変パラメータがある法則に従って 自己調整されること」と定義できよう。従って, 最適化ア ルゴリズムにおけるパラメータ調整戦略とアルゴリズムの 適応性に関しては以下のように整理できる。

(1) パラメータ固定則

予めパラメータを設定し，探索過程でパラメータを変 化させることなく探索する機構

(2) スケジューリング的調整則

予め定められたスケジュールに従って，パラメータを 調整する機構

(3) 反応的調整則

探索過程において，予め定めた何らかの条件を満たし た際にパラメータを調整する機構

(4) 適応的調整則

予め外部から探索の指針となる何らかの情報を与えた 上で，探索過程で得られた情報から，探索の指針に従 うようパラメータを調整する機構

(5) 自律適応的調整則

探索過程で得られた内部情報から指針を作成および改 善し , パラメータを調整する機構

PSOの適応化に関するこれまでの研究としては, スケジュー リング的調整則 ${ }^{(2)}$ ，反応的調整則 ${ }^{(4)}{ }^{(5)}$ ，適応的調整則 ${ }^{(8)}$ が行われており，適応性のレベルが上がるに従い，多樣な 問題を効率良く解けることが報告されている。

本論文では, 上述の分類における適応的調整則を有する PSO の開発，中でも外部からの情報をできるだけ利用し ない高度な適応性を有するアルゴリズムの開発を目指し， PSO の探索過程で得られる最良解情報を利用した適応型 PSO を提案する。

\section{PSO の可調整性評価と適応化}

最適化アルゴリズムの適応化を実現するには 「パラメー 夕の調整と探索の成否 (効率的な最適解探索) との間に何 らかの定性的あるいは定量的な関係を見出し得ること」が 必要となる。我々はこの関係を「アルゴリズムの可調整性」 と呼んでいる。本章では，PSO のパラメータ設定と探索の 成否を数值実験に基づいて検証し, 最良解 gbest の更新頻 度と探索の成否 (効率的な最適解探索) との間に高い相関 があることを明らかにする。

なお，PSO にはさまざまなレベルでパラメータの自由度 を考えることができるが(2)，本論文では最も一般的なパラ メータである 3 つの重み係数 $w, c_{1}, c_{2}$ の内 $, c_{1}, c_{2}$ を調 
整可能なパラメータとして考えることとする。さらに, 2 章で概説した一般的な PSO ではこれらの 2 つのパラメー タはすべての Particle に対して同一の值か設定されること

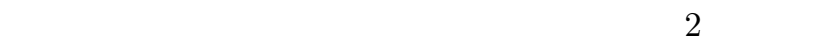
メータは Particle ごとに独立に設定できるものとしている 点に注意されたい。

〈3. 1〉PSOにおける探索の成否一般に,最適化に おける探索の成功とは, 大域的最適解または良好な準最適 解の効率的および安定な発見を指す。本論文では，探索の 成功へつながるであろう 1 つの指針として, gbest を可能 な限り多く更新すること」を探索の目標と仮定する。PSO において，gbestの更新はより良い解を探索した際に行わ れるため，初期值依存性もあるが，少なくとも gbest を更 新することが直接的に最適性の低下へつながる可能性は極 めて低く, 更新回数が多いことは結果的に効率的な最適解 探索を実現できる可能性が高いと予想できる。以上のこと を踏まえ，以下では, gbest の更新頻度とパラメータとの 関係 (PSO の可調整性) を典型的なベンチマーク問題を用 いた数值実験に基づいて検証する。

〈3. 2〉PSO の可調整性の検証探索過程で適応的に パラメータを調整することにより，探索効率の向上を実現 するためには, PSO のパラメータと gbestの更新との間に 何らかの定量的・定性的関係が存在しなければならない。 本論文では以下の 3 つの点から上述の関係の存在について 検証する。

(1) gbest の更新可能性

(2) gbest の更新頻度

(3) gbest の更新頻度と gbest 改善度

ここで, gbest 改善度とは, 探索終了時および初期状態にお ける最良解評価値 $f($ gbest $)$ の数值的な差 $\mid f\left(g_{\text {best }} \mathrm{T}_{\text {max }}\right)-$ $f\left(\right.$ gbest $\left.^{0}\right) \mid$ を示す。PSO のパラメータ設定と gbest の更新 可能性・更新頻度の間に何らかの関係が存在すれば，光の 関係を利用してパラメータを適応的に調整することにより， gbest の更新頻度の増加を実現できる。更に , gbest 更新頻 度と gbest 改善度とが比例関係であるならば，更新頻度の 増加により最良解評価值をより多く改善し，結果として解 の精度を向上できる可能性がある。なお，本論文では既に 述べたように基礎的検討段階としてPSOの 2 つのパラメー 夕 $c_{1}, c_{2}$ に着目した解析と適応化を行うこととする。

数値実験では, 典型的なベンチマーク問題である $\left(f_{1}^{n}: 2^{n}\right.$ minima function (付 1) と $f_{2}^{n}: n$-dimensional Griewank function (付 2)) を対象とした。表 1 にシミュレーション 条件を示す。重み係数 $c_{1}, c_{2}$ の值は, 各 Particle ごとに 表 1 に示す設定範囲内で一樣乱数により決定し，パラメー タを固定した状態で上述の 2 つのベンチマーク問題に適用 する。

图 2 は，上述のシミュレーション条件のもとで，光れぞ れのベンチマーク問題 (100 次元) に対して 500 回の試行 を行った結果，1 回以上 gbest を更新したParticle のパラ メータ值をすべてプロットしている。これらの図において
表 1 シミュレーション条件

Table 1. Condition of simulation.

\begin{tabular}{l||c}
\hline \multicolumn{1}{c||}{ Parameter } & Value \\
\hline \hline Number of Particles $m$ & 20 \\
Total number of iterations $\mathrm{T}_{\max }$ & 500 \\
Total number of runs & 500 \\
Parameter of PSO $w$ & 0.8 \\
Parameters of PSO $c_{1}$ and $c_{2}$ & $0<c_{1}, c_{2}<3.0$ \\
\hline
\end{tabular}

プロットがない範囲は, 500 回の試行において 1 度も gbest が更新されなかったパラメータ領域を示す。

著者らは問題の次元を变えて同樣の数值実験を数多く行っ ているが, gbest の更新が行われる領域は図 2 と同樣に

$0<c_{1}+c_{2} \leq 3$

で描かれる領域に集中していることを確認している。つま り, gbest の更新が行われる領域，すなわち更新可能性領 域はパラメータの初期值範囲や問題によらず，ほぼ一致し ていることを意味する。しかしながら，更新の可能性が保 障されたとしても，可調整性の最終的な目標である「gbest を多く更新すること」を実現できる保障はないことに注意 されたい。

一方，図 3 は，500 回の試行における 2 つのパラメータ $c_{1}, c_{2}$ の值に対する更新頻度の分布を表している。パラメー 夕值を 0.05 間隔で分割し, 各範囲のパラメータ值に設定さ れた複数の Particle に対する gbest 更新回数の平均值を示 している。この結果から， $c_{1}, c_{2}$ 両パラメータに対して， 比較的更新頻度が高いパラメータ值範囲が存在することが 分かる。さらに，ある単一のパラメータのみが非常に多く 更新するような偏りは有していない点も重要である。

図 4 は, 500 回の試行における更新頻度と gbest 平均改 善度との相関関係を示している。初期値によらず，平均的 に更新頻度が多くなるにつれて，結果的に得られる gbest 改善度は多くなることが確認できる。

以上の数值実験により，パラメータと最良解の更新，お よび更新頻度と gbest 改善度との間に強い相関があること が確認された。従って, gbest 更新頻度に着目することに より，パラメータ設定と得られる解の精度とに強い相関が あることが確認され，これらを利用することにより効率的 な探索を実現できる可能性が高い。

\section{4. 適応型PSO の提案と探索性能の検証}

本章では，これまでの検討結果を踏まえ，最良解情報を 用いたPSO の適応化に関する基本的な方針をまとめる。さ らに, 提案する適応型 PSO のアルゴリズムを示し , 最後 にベンチマーク問題を用いた数值実験により，提案アルゴ リズムの有用性を検証する。

〈4. 1〉 最良解情報を用いた PSO の適応化 工学的 応用の観点からは, Particle 自身が探索過程で得ることが できる情報を用いて，適応的にパラメータを調整する適応 型アルゴリズムが望ましい。しかし，適応型アルゴリズム 


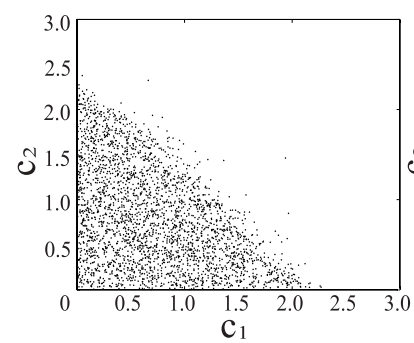

(1) $f_{1}^{100}\left(2^{\mathrm{n}}\right.$ minima $)$

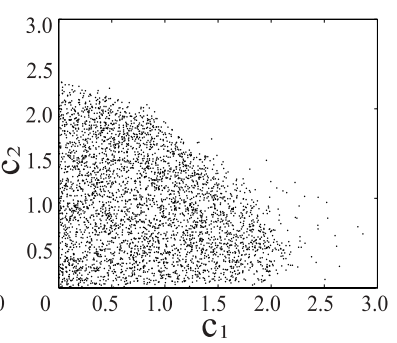

(2) $f_{2}^{100}$ (Griewank)
図 2 最良解 gbest の更新可能領域

Fig. 2. Region where global best gbest is updated.

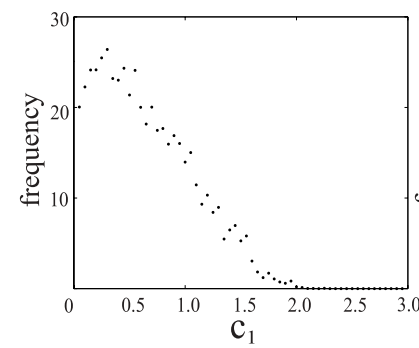

(1) $f_{1}^{100}\left(2^{\mathrm{n}}\right.$ minima $)$

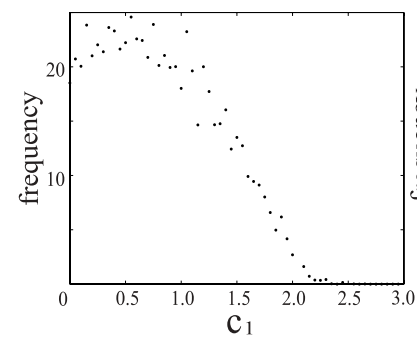

(3) $f_{2}^{100}$ (Griewank)

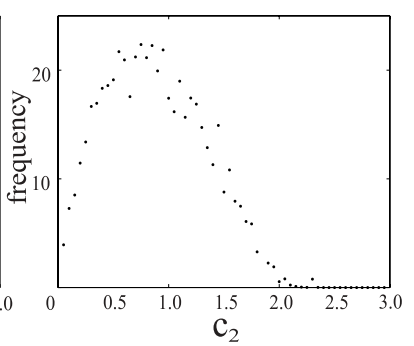

(2) $f_{1}^{100}\left(2^{\mathrm{n}}\right.$ minima $)$

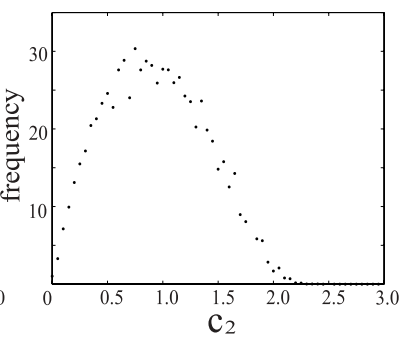

(4) $f_{2}^{100}$ (Griewank)
図 3 最良解 gbest の更新頻度分布

Fig. 3. Distribution of frequency for updated global best gbest.

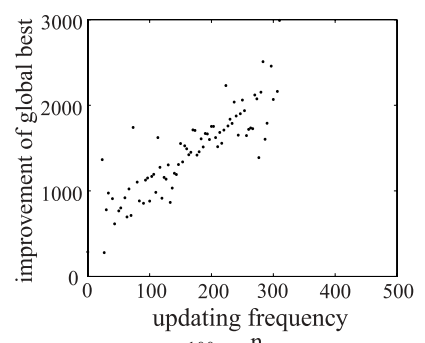

(1) $f_{1}^{100}\left(2^{\mathrm{n}}\right.$ minima $)$

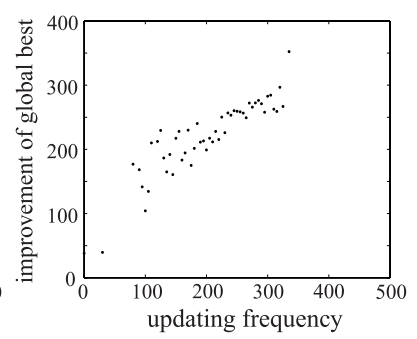

(2) $f_{2}^{100}$ (Griewank)
図 4 更新頻度と gbest 改善度との相関関係

Fig. 4. Correlation between frequency and range of updated global best gbest.

の構築には課題が多く，どのようなレベルの適応化を目指 すかなど，試行錯誤を要することが多い。適応化における 重要な項目は以下のように整理できよう。

(1) アルゴリズム内部で探索の改善につながる情報を得る。

(2) 探索状況を判断し，探索の指針を，作成および改善す ることにより見出す。

(3) 作成した探索の指針により自己改善を行う。
適応型，あるいは自律適応型アルゴリズムの構築は, 知的 エージェントの実現と関連が深いと思われるが，本論文で は, 「Particle が予め持つ何らかの指針」に重点を置いてい る。工学において対象とする多くの問題では, 近接最適性 の原理 (Proximate Optimality Principle) に代表される ような，何らかの「偏り」が存在することが知られており， PSO は光れらを利用した有効な手法の中の 1 つである。 従って，工学においては多くの問題に共通したなんらかの 「偏り」をいかに捉えるかも重要となると考えられる。

自己改善を実現するために探索過程で得られるどのよう な情報を用いるか，また得られる情報をどのように活用して 自己改善を実現するかについての概要は以下の通りである。

$\langle 4 \cdot 1$ 1 1 内部情報本論文では, 探索過程で自己改善 のために利用する情報は, 各々のParticleの持つパラメータ 值および更新頻度情報とする。各 Particle はある Particle のパラメータ值を参考に自己改善を行う。ある Particle と は, gbest を更新した Particleである。

〈4.1․ 2〉探索の指針 各々の Particle は, 最良解 gbest を更新することを目的とし，更新式による移動の度に 得られる評価値を最小とするようにパラメータを調整しな がら探索する。本アルゴリズムでは，既存の情報の利用に 留まり学習機構は排除されているが, 可調整性の検証によ り gbest 更新情報を利用することにより探索効率の向上を 実現できる可能性があることがわかっており，各 Particle は，予め探索効率向上を達成する 1 つの指針を有している。

〈4 1.3〉自己改善 本アルゴリズムでは, 目標パラ メータ值へと Particle のパラメータを漸近させることによ り自己改善を行う。しかし, 単に gbestを更新したものを 自己改善の指針とするのではなく，少なくとも自身より優 れている，つまり更新頻度の高いものであった場合に改善 を行うものとする。自身より更新頻度の低い Particle の持 つパラメータ值に近づける操作は, 探索効率の改善に結び 付かない可能性が高い。

本論文では, 各 Particle のパラメータ改善として, 式 (4) および式 (5) に示す改善式を提案する。ここで, ステ ップ幅 $\alpha_{i}, i=1,2, \cdots, m, c_{1 i}, i=1,2, \cdots, m$ および $c_{2 i}, i=1,2, \cdots, m$ は各 Particle ごとに互いに独立に調整 される。 $\alpha_{i}$ は, 個々の Particle か探索の進捗状況に応じて， 0 もしくは $1 / \mathrm{T}_{\max }$ の 2 值を選択するものとする。ここで， cbest $_{1}$ と cbest ${ }_{2}$ とは, あるイテレーションにおいて gbest を更新した Particle $i$ の持つパラメータ值である。 $\alpha_{i}$ につ いては, 0 および総イテレーション数 $\mathrm{T}_{\max }$ の逆数とする ことで, 簡易な構造を実現している。

$$
\begin{aligned}
& c_{1 i}^{k+1}=c_{1 i}^{k}+\alpha_{i}^{k}\left(\text { cbest }_{1}^{k}-c_{1 i}^{k}\right), i=1,2, \cdots, m \\
& \ldots \ldots \ldots \ldots \ldots \ldots \\
& c_{2 i}^{k+1}=c_{2 i}^{k}+\alpha_{i}^{k}\left(\operatorname{cbest}_{2}^{k}-c_{2 i}^{k}\right), i=1,2, \cdots, m \\
& \alpha_{i}^{k}=\left\{\begin{array}{l}
0 \\
1 / \mathrm{T}_{\max }
\end{array}\right.
\end{aligned}
$$


〈4. 2〉最良解情報を用いた適応型 PSO のアルゴリズ 厶 本論文で提案する最良解情報を用いた適応型 PSO (Adaptive PSO) のアルゴリズムは以下の通りである。

\section{【最良解情報を用いた適応型 PSO】}

Step0:[準備] 探索点の総数を $m:=20$, 重み係数を $w:=0.8$, 反復回数のカウンターを $k:=1$ とする。 更に, 最大反復回数 $\mathrm{T}_{\text {max }}$ を設定する。

Step1:[初期化] 各 Particle の初期位置 $\boldsymbol{x}_{i}^{1}$ と初期速度 $\boldsymbol{v}_{i}^{1}$ を乱数によって決める。更に，重み係数 $c_{1 i}^{1}, c_{2 i}^{1}$ を $0<c_{1 i}^{1}<3,0<c_{2 i}^{1} \leq\left(3-c_{1 i}^{1}\right), i=1,2, \cdots, m$ に 示す範囲内で乱数により決定する。gbest 更新回数の カウンターを $g_{i}:=0, i=1,2, \cdots, m$ とする。

pbest $_{i}^{1}:=\boldsymbol{x}_{i}^{1}, i=1,2, \cdots, m$

gbest $^{1}:=$ pbest $_{i_{g}}^{1}$

とおく。ただし, $i_{g}=\arg \min f\left(\boldsymbol{p b e s t}_{i}^{1}\right)^{\dagger}$

Step2: [速度及び位置の更新] 各 Particle の速度 $\boldsymbol{v}_{i}$ およ び位置 $\boldsymbol{x}_{i}$ を次式で更新する。

$v_{i j}^{k+1}:=w \cdot v_{i j}^{k}+c_{1 i}^{k} \cdot \operatorname{rand}_{1}() \cdot\left(\right.$ pbest $\left._{i j}^{k}-x_{i j}^{k}\right)$ $+c_{2 i}^{k} \cdot \operatorname{rand}_{2}() \cdot\left(\right.$ gbest $\left._{j}^{k}-x_{i j}^{k}\right)$

$x_{i j}^{k+1}:=x_{i j}^{k}+v_{i j}^{k+1}, i=1,2, \cdots, m ; j=1,2, \cdots, n$

Step3: [最良解情報 pbest 及び gbest の更新]

$I_{1}=\left\{i \mid f\left(\boldsymbol{x}_{i}^{k+1}\right)<f\left(\boldsymbol{p b e s t}_{i}^{k}\right), i=1,2, \cdots, m\right\}$

とし,

pbest $_{i}^{k+1}:=\boldsymbol{x}_{i}^{k+1}, i \in I_{1}$

pbest $_{i}^{k+1}:=$ pbest $_{i}^{k}, i \notin I_{1}$

$\boldsymbol{g}_{\boldsymbol{b e s t}} \boldsymbol{t}^{k+1}:=\boldsymbol{p}_{\boldsymbol{b}} \boldsymbol{e} \boldsymbol{t}_{i_{g}}^{k+1}$

とおく。ただし,$i_{g}=\arg \min f\left(\boldsymbol{p b e s t}_{i}^{k+1}\right)$

Step4:[パラメータ $\alpha$ の決定]

$f\left(\boldsymbol{p b e s t}_{i_{g}}^{k+1}\right) \geq f\left(\boldsymbol{g}_{\boldsymbol{b} e \boldsymbol{s} \boldsymbol{t}^{k}}\right)$ であれば，

$\alpha_{i}^{k}:=0, i=1,2, \cdots, m$ とする。さもなければ,

$g_{i_{g}}:=g_{i_{g}}+1$

$I_{2}=\left\{i \mid g_{i}<g_{i_{g}}, i \neq i_{g}, i=1,2, \cdots, m\right\}$

$\alpha_{i}^{k}:=0, i \notin I_{2}$

$\alpha_{i}^{k}:=1 / \mathrm{T}_{\max }, i \in I_{2}$

とする。

Step5:[パラメータ $c_{1}$ および $c_{2}$ の更新 $]$

$c_{1 i}^{k+1}:=c_{1 i}^{k}+\alpha_{i}^{k}\left(\right.$ cbest $\left.t_{1}^{k}-c_{1 i}^{k}\right)$

$c_{2 i}^{k+1}:=c_{2 i}^{k}+\alpha_{i}^{k}\left(\right.$ cbest $\left._{2}^{k}-c_{2 i}^{k}\right)$

Step6:[終了判定] $k=\mathrm{T}_{\max }$ を満たしていれば終了。さ もなければ $k:=k+1$ として Step 2 へ行く。

〈4. 3〉 ベンチマーク問題を用いた数值実験 今回対 象とする問題は, ベンチマーク問題の 1 つである単峰性関 数 $f_{1}$ : Rosenbrock's saddle 関数 (付 3 ), 及び多峰性関数 $f_{2}: 2^{n}$ minima 関数 (付 1) および $f_{3}:$ Griewank 関数 (付

2) とする。 $f_{2}, f_{3}$ は共に多峰性関数であるが, 次元相関を もつかどうかといった点で構造的相違がある。

パラメータ固定型の PSO (以下 , PSO) および一般的

\footnotetext{
$\dagger \arg \min$ は, 最小値を実現する变数值を表す
}

表 2 パラメータ調整則

Table 2. Adjustment rules for parameters.

\begin{tabular}{c||c|c}
\hline \hline & PSO & LDIWA \\
\hline \hline Initial value & $w=0.7$ & $w=0.9$ \\
& $c_{1}=c_{2}=2.0$ & $c_{1}=c_{2}=2.0$ \\
\hline $\begin{array}{c}\text { Adjustment } \\
\text { rule }\end{array}$ & Constant & $w^{k+1}=w^{k}$ \\
\hline Last value & $w=0.7$ & $\begin{array}{c}\text { w } \\
\end{array}$ \\
& $c_{1}=c_{2}=2.0$ & $c_{1}=c_{2}=2.0$ \\
\hline
\end{tabular}
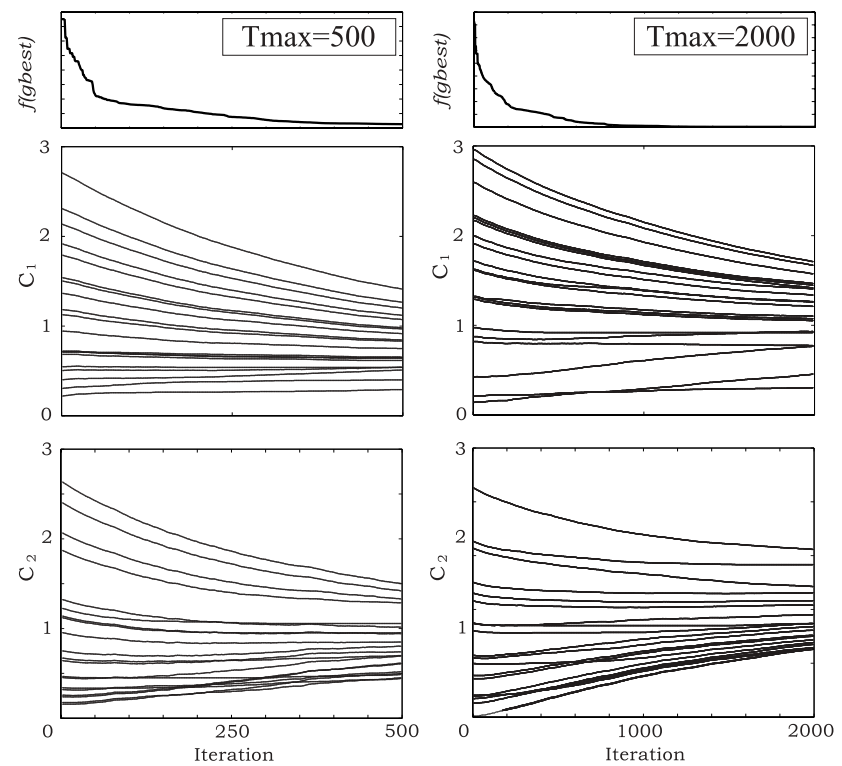

図 $5 c_{1}, c_{2}$ の推移 $\left(\mathrm{T}_{\max }=500,2000\right)$

Fig. 5. Transition of $c_{1}$ and $c_{2}\left(\mathrm{~T}_{\max }=500,2000\right)$.

に性能が良いとされている Linearly Decreasing Inertia Weight Approach ${ }^{(2)}$ (以下, LDIWA) と，提案する適応 型 PSO (以下, APSO) を比較することにより, 提案手法 (APSO) の有用性を検証する。更に，提案手法における Step4: , Step5:の調整操作を除いた PSO (以下, PPSO) とも比較を行い, 調整操作の有無による性能評価を行う。具 体的なパラメータ設定は表 2 の通りである。なお，LDIWA では各次元における速度成分の大きさを制約範囲内に抑え る速度制限機構が付加されており，提案手法の初期固定パ ラメータとして, Particle 数 $m=20, w=0.8$ とした。

図 5 にイテレーション数に対するパラメータ $c_{1}, c_{2}$ の推 移を示す。提案手法の多樣化・集中化のバランスを確認す るため, 評価值の推移も示している。2つのパラメータ $c_{1}$, $c_{2}$ は一定の範囲に収束していることか確認できる。しかし， ある值へと完全に収束することはなく，探索後半において もパラメータの多樣性が維持されていることに注意された い。評価値の推移については， $\mathrm{T}_{\max }=500$ において多樣 化から集中化へと移行していることは確認できるが，十分 に収束してはいない。しかし， $\mathrm{T}_{\max }=2000$ であれば，探 索後半において十分に収束していることが確認できる。

図 3 に示される数值実験結果より, 特定のパラメータ値 
表 $3 f_{1}$ :Rosenbrock's saddle 関数における性能比較 $\left(\mathrm{T}_{\max }=500\right)$

Table 3. Application results for $f_{1}$ :Rosenbrock's saddle function $\left(\mathrm{T}_{\max }=500\right)$.

\begin{tabular}{|c|c|c|c|c|c|c|c|c|c|c|c|c|c|}
\hline \multirow[b]{2}{*}{ Dim. } & \multirow{2}{*}{$\begin{array}{c}\text { Global } \\
\text { optimum }\end{array}$} & \multicolumn{4}{|c|}{ Best value } & \multicolumn{4}{|c|}{ Mean value } & \multicolumn{4}{|c|}{ Worst value } \\
\hline & & PSO & LDIWA & PPSO & APSO & $\mathrm{PSO}$ & LDIWA & PPSO & APSO & PSO & LDIWA & PPSO & APSO \\
\hline 10 & 0 & 0 & 0.2 & 0.1 & 0.0 & 0.4 & 1.7 & 1.1 & 0.7 & 1.6 & 6.3 & 2.3 & 2.0 \\
\hline 50 & 0 & 8.2 & 10.2 & 15.1 & 8.6 & 14.9 & 39.6 & 48.3 & 14.0 & 32.3 & 215.1 & 134.9 & 43.3 \\
\hline 100 & 0 & 28 & 115 & 464 & 38 & 165 & 612 & 1412 & 117 & 670 & 3325 & 3628 & 359 \\
\hline 500 & 0 & 82194 & 81972 & 7589 & 5292 & 93847 & 93218 & 24174 & 13145 & 105799 & 103154 & 80503 & 37778 \\
\hline
\end{tabular}

表 $4 f_{2}: 2^{n}$ minima 関数における性能比較 $\left(\mathrm{T}_{\max }=500\right)$

Table 4. Application results for $f_{2}: 2^{n}$ minima function $\left(\mathrm{T}_{\max }=500\right)$.

\begin{tabular}{|c|c|c|c|c|c|c|c|c|c|c|c|c|c|}
\hline \multirow[b]{2}{*}{ Dim. } & \multirow{2}{*}{$\begin{array}{c}\text { Global } \\
\text { optimum }\end{array}$} & \multicolumn{4}{|c|}{ Best value } & \multicolumn{4}{|c|}{ Mean value } & \multicolumn{4}{|c|}{ Worst value } \\
\hline & & $\mathrm{PSO}$ & LDIWA & PPSO & APSO & PSO & LDIWA & PPSO & APSO & PSO & LDIWA & PPSO & APSO \\
\hline 10 & -783 & -783 & -783 & -783 & -783 & -744 & -774 & -753 & -761 & -668 & -726 & -691 & -698 \\
\hline 50 & -3916 & -2072 & -3339 & -3381 & -3474 & -1401 & -2923 & -2991 & -3225 & -948 & -2338 & -2398 & -2991 \\
\hline 100 & -7833 & -3025 & -3892 & -6021 & -6166 & -2172 & -2434 & -4846 & -5538 & -1556 & -1499 & -3454 & -3972 \\
\hline 500 & -39165 & -8977 & -8686 & -18516 & -19865 & -7413 & -6801 & -15148 & -16372 & -5934 & -5200 & -6609 & -6242 \\
\hline
\end{tabular}

表 $5 f_{3}$ : Griewank 関数における性能比較 $\left(\mathrm{T}_{\max }=500\right)$

Table 5. Application results for $f_{3}$ : Griewank function $\left(\mathrm{T}_{\max }=500\right)$.

\begin{tabular}{|c|c|c|c|c|c|c|c|c|c|c|c|c|c|}
\hline \multirow[b]{2}{*}{ Dim. } & \multirow{2}{*}{$\begin{array}{l}\text { Global } \\
\text { optimum }\end{array}$} & \multicolumn{4}{|c|}{ Best value } & \multicolumn{4}{|c|}{ Mean value } & \multicolumn{4}{|c|}{ Worst value } \\
\hline & & $\mathrm{PSO}$ & LDIWA & PPSO & APSO & $\mathrm{PSO}$ & LDIWA & PPSO & APSO & $\mathrm{PSO}$ & LDIWA & PPSO & APSO \\
\hline 10 & 0 & 0.1 & 0.0 & 0.0 & 0.0 & 0.5 & 0.1 & 0.1 & 0.1 & 1.0 & 0.3 & 0.7 & 0.4 \\
\hline 100 & 0 & 342.8 & 49.12 & 12.6 & 7.54 & 421.1 & 90.9 & 46.5 & 18.88 & 474.2 & 138.7 & 97.2 & 35.8 \\
\hline 500 & 0 & 1931 & 2293 & 481 & 448 & 2314 & 2413 & 962 & 663 & 2476 & 2523 & 1622 & 1081 \\
\hline
\end{tabular}

表 6 gbest 更新頻度比較 $\left(\mathrm{T}_{\max }=500\right)$

Table 6. Comparison of frequency for updated global best gbest $\left(\mathrm{T}_{\max }=500\right)$.

\begin{tabular}{c||c|c|c|c|c|c|c|c|c|c|c|c}
\hline \hline \multicolumn{1}{c||}{} & \multicolumn{3}{c|}{$f_{1}:$ Rosenbrock's saddle } & \multicolumn{4}{c|}{$f_{2}: 2^{n}$ minima } & \multicolumn{4}{c}{$f_{3}:$ Griewank } \\
\cline { 2 - 12 } Dim. & PSO & LDIWA & PPSO & APSO & PSO & LDIWA & PPSO & APSO & PSO & LDIWA & PPSO & APSO \\
\hline 10 & 26.3 & 65.4 & 218 & 233 & 147 & 139 & 223 & 310 & 77.1 & 127 & 204 & 260 \\
50 & 3.4 & 55.3 & 275 & 314 & 90.0 & 141 & 242 & 402 & 17.0 & 110 & 299 & 421 \\
100 & 1.8 & 48.7 & 267 & 313 & 91.9 & 73.3 & 210 & 399 & 10.9 & 98.8 & 284 & 421 \\
500 & 5.0 & 7.1 & 206 & 273 & 98.1 & 67.5 & 144 & 374 & 28.1 & 27.9 & 236 & 399 \\
\hline \hline
\end{tabular}

付近に gbest の更新頻度分布が偏っているわけではないこ とが示されていることを考慮すれば , パラメータが一定の 多樣性を持っていることは当然予想される。著者らは既に， PSO のパラメータの多樣性が多樣な問題に対する探索性能 を維持する能力，すなわち最適化アルゴリズムのロバスト 性向上に寄与することを確認しており，ロバスト性の観点 からも提案するアルゴリズムは有効であると考えられる。

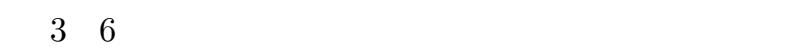
て各手法を 100 回ずつ試行し，光れにより得られた評価值 の最悪値, 平均値, 最良値, および平均更新回数を示して いる。数值実験より, パラメータ固定型の PSO は, 問題 の次元数の増加に伴い, 大域的最適解の探索性能が著しく 低下することが分かる。つまり, パラメータ固定型の PSO は問題に応じた適切なパラメータを採用したとしても次元 に増加に対する大域的最適解探索性能の低下という問題が あり，さらにパラメータチューニングの労力や困難さを考 慮すれば , パラメータの適応化は重要な課題となる。

スケジューリング的調整則の一手法である LDIWA につ いては，低次元であれば解の劣化はほとんど見られないが，
ある次元数を境に著しく最適性が低下することが分かる。 境界となる次元数はイテレーション数に依存し，十分に利 用者が時間をかけられるのであれば，高次元問題であって も効率的探索を実現できる可能性はある。しかし，現実的 には無限には時間をかけることは不可能であり，このよう な観点からも LDIWA は低次元問題に適したアルゴリズム であると考えられる。

一方，調整操作を除いた提案手法 PPSO は低次元の問 題から高次元問題に亘って, パラメータ固定型の PSO や LDIWA と比較して解の劣化が少ないことが分かる。これ は, 初期値におけるパラメータの多樣性が有効であること を示している。更に，PPSO に比へ提案手法の方が得られ る解の最適性，更新回数共に向上していることからも，パ ラメータの多樣性に加え, 提案手法におけるパラメータ調 整についても有効であることか確認できる。つまり，提案 手法は幅広いクラスの問題に対して適応可能なアルゴリズ ムであると言えよう。

本論文では，探索の成功を「多くgbest を更新すること」 と捉え，提案アルゴリズムでは多く gbestを更新するよう 
にパラメータを調整しているが, 提案アルゴリズムの更新 頻度は LDIWA の数倍の更新頻度を実現していることから も本論文における目標は十分達成されていると考える。

\section{5. おわりに}

本論文では，PSO における最良解の更新頻度とパラメー 夕設定における定性的関係をベンチマーク問題を用いた数 値実験により明らかにした。光して, 最良解更新頻度が高 い Particle のパラメータ值に漸近するように個々の Particle のパラメータを適応的に調整する適応型 PSO を構筑し た。典型的なベンチマーク問題である Rosenbrock's saddle

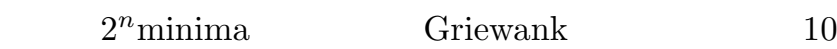
次元から 500 次元) を用いて提案する適応型 PSO と従来 の PSO (パラメータ固定型 PSO とスケジュール的調整型 $\mathrm{PSO})$ と比較した結果, 最良解更新頻度で約 2 倍から 10 倍, 最終的に得られた最良解も提案アルゴリズムが最も優 れていることを検証した。

適応化を目指すにあたり，Particle の特徵を捉え，いか に個々の Particle を適応的に探索させるかといった視点が 重要となってくると考えられる。提案アルゴリズムでは， Particle が予め持つ探索の指針に重点を置いており，Particle の特徵・知性に関しては, 考慮すべき事項が非常に多 く残されている。マルチェージェントにおける強化学習等 に代表されるように，探索の履歴を効率よく利用すること により，一層の探索効率改善が見込まれるであろう。これ らについて検討し，より自律的・効率的なアルゴリズムを 構築することが本論文の重要な課題であるが , 本論文によ り，PSO に基づいた適応型アルゴリズムの 1 つの形態が実 現されたものと考える。

(平成 17 年 5 月 2 日受付, 平成 17 年 9 月 21 日再受付)

文献

（1）森下 巌：適応システム，産業図書 (1975)

( 2 ) J. Kennedy and R.C. Eberhart: "Swarm Intelligence", Morgan Kaufmann Publishers (2001)

(3) K.E. Parsopoulos and M.N. Vrahatis: "Recent Approaches to Global Optimization Problems through Particle Swarm Optimization", Natural Computing, Vol.1, No.2-3, pp.235-306 (2002)

(4) $\mathrm{Hu}, \mathrm{X}$. and R.C. Eberhart: "Adaptive Particle Swarm Optimization: Detection and Response to Dynamic Systems", Proceedings of The IEEE Congress on Evolutionary Computation (CEC 2002), pp.1666-1670 (2002)

(5) A. Ide and K. Yasuda: "A Basic Study of The Adaptive Particle Swarm Optimization", IEEJ Trans. on EIS., Vol.124-C, No.2, pp.550-557 (2004-2) (in Japanese)

井出 東・安田恵一郎：「適応型 Particle Swarm Optimization に 関する基礎的検討」, 電学論 C , 124, 2, pp.550-557 (2004-2)

( 6 ) K. Yasuda, A. Ide, and N. Iwasaki: "Stability Analysis of Particle Swarm Optimization", Proceedings of The Fifth Metaheuristics International Conference, MIC03-34 (Aug. 2003)

( 7 ) K. Yasuda A. Ide, and N. Iwasaki: "Adaptive Particle Swarm Optimization", Proceedings of 2003 IEEE International Conference on Systems, Man \& Cybernetics, TA8-1, pp.1554-1559 (Oct. 2003)

(8) K. Yasuda and N. Iwasaki: "Adaptive Particle Swarm Optimization using Velocity Information of Swarm", Proceedings of 2004 IEEE International Conference on Systems, Man \& Cybernetics, pp.3475-3481 (Oct. 2004)

\section{付 録}

1. 本論文で用いたベンチマーク問題

(1) $2^{n}$ minima problem

$$
\begin{aligned}
& \min . \quad f(x)=\sum_{i=1}^{n}\left(x_{i}^{4}-16 x_{i}^{2}+5 x_{i}\right) \\
& \text { subj. to } \quad-5 \leq x_{i} \leq 5, \quad i=1, \cdots, n
\end{aligned}
$$

(2) Griewank problem

$$
\begin{aligned}
& \min . \quad f(\boldsymbol{x})=\frac{1}{4000} \sum_{i=1}^{n} x_{i}{ }^{2}+\prod_{i=1}^{n} \frac{x_{i}}{\sqrt{i}} \\
& \text { subj. to }-250 \leq x_{i} \leq 250, \quad i=1, \cdots, n
\end{aligned}
$$

(3) Rosenbrock's saddle problem

$$
\begin{aligned}
& \text { min. } f(x)=\sum_{i=1}^{n-1}\left\{100\left(x_{n}^{2}-x_{n+1}\right)^{2}+\left(1-x_{n}\right)^{2}\right\} \\
& \text { subj. to } \quad-2 \leq x_{i} \leq 2, \quad i=1, \cdots, n
\end{aligned}
$$

山口 晃 歓 (学生員) 2005 年 3 月東京都立大学工学部電気

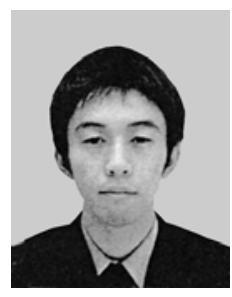
工学科卒業。同年 4 月, 同大学大学院工学研究科 電気工学専攻修士課程進学, 現在に至る。システ 么最適化に関する研究に従事。

岩 崎 信 弘 (正員) 2005 年 3 月東京都立大学大学院工学研

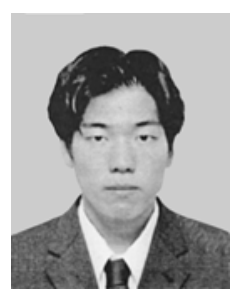
究科電気工学専攻修士課程修了。同年 4 月, 東京 電力 (株) 入社, 現在に至る。システム最適化に 関する研究に従事。

安 田 恵一郎 (正員) 1989 年 3 月北海道大学大学院工学研究

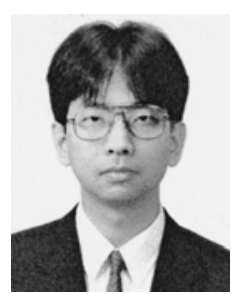
科電気工学専攻博士課程修了。同年 4 月東京都 立大学工学部助手, 91 年 4 月同大工学部助教授， 現在, 同大学大学院工学研究科助教授。システム 最適化手法ならびに電カシステム工学の研究に従 事。工学博士。 